\title{
Effects of Feeding Frequency and Handling on Growth and Mortality of Cultured Walking Catfish Clarias fuscus
}

\author{
Brian J. BuUrma and James S. Diana ${ }^{1}$ \\ School of Natural Resources, University of Michigan, Ann Arbor, Michigan 48109-1115 USA
}

\begin{abstract}
Two experiments were conducted to study the effects of feeding frequency on growth, and of handling stress on growth and mortality, in intensive tank culture of the walking catfish Clarias fuscus. In the first experiment, fish were grown from an initial weight of $37 \mathrm{~g}$ for $34 \mathrm{~d}$. A fixed ration of $3.0 \%$ body weight per day was divided into either 1,2 , or 3 feedings per day, and fish were either handled weekly or left unhandled for the entire experiment. Fish given 3 feedings per day experienced $19 \%$ faster growth $(P<0.05)$ than fish given the same ration in a single feeding per day. These differences in growth reflect differences in assimilation efficiency, assuming all other metabolic costs were constant among treatments. Handling of individuals caused decreased growth; however, there was no effect on mortality.

In the second experiment, fish were grown from an initial weight of $78 \mathrm{~g}$ for $29 \mathrm{~d}$. Fish were fed either 1 or 2 satiation feedings per day and were either handled weekly or left unhandled for the entire experiment. Fish fed 2 satiation feedings per day experienced $47 \%$ faster growth $(P<0.05)$ than fish fed 1 satiation feeding per day, which was assumed to reflect a higher level of food consumption. No effect of handling on either growth or mortality was observed for fish in experiment 2. Multiple meals per day also reduced depensatory growth among individuals in both experiments.
\end{abstract}

When supplemental feed is administered in fish culture, the primary objective is to maximize growth per unit feed. Given an adequate protein intake, fish growth is related to the amount of energy assimilated, which in turn depends upon two important variables - voluntary food consumption and assimilation efficiency (Webb 1978; Brett 1979; Diana et al. 1988). Assimilation efficiency is the fraction of ingested food which is absorbed. Feeding frequency is an important factor affecting both voluntary food consumption and assimilation efficiency (Brett 1971; Windell 1978). It is essential to understand the effects of feeding frequency on consumption and assimilation in order to optimize feeding practices in a culture system.

Many studies of feeding frequency in fish have employed satiation feeding in the laboratory, where increased growth occurred in response to increased food consumption that occurred with higher meal frequency

' Corresponding author.
(Andrews and Page 1975; Hogendoorn 1981; Marian et al. 1981; Sampath 1984). Differences in assimilation efficiency or nitrogen excretion rates that occurred with higher meal frequency could be detected by differences in feed conversion. During the above laboratory studies, it was possible to accurately quantify food consumption, since feeding rate was closely monitored and corrected for uneaten feed. Food application rate does not necessarily equal food consumption rate in larger scale commercial systems, since a significant and unknown portion of administered food may not be eaten (Yamada 1985).

This study of fish feeding frequency employed a two-stage method that was more applicable for commercial-type systems (Grayton and Beamish 1977). Absolute ration size was fixed at a level below satiation in the first set of experiments, and we assumed complete ingestion of the ration and a constant energy expenditure due to metabolism at this fixed ration. If these assumptions are met, differences observed in growth for experiment 1 (when meal fre- 
quency is increased but absolute ration remains constant) must reflect differences in assimilation efficiency. If fish were then fed to satiation during each feeding in experiment 2 , and assimilation efficiency as well as metabolism was assumed to be constant between treatments, then differences in growth reflect differences in voluntary food consumption with meal frequency treatments.

Walking catfishes Clarias sp. are highly suitable for high density, intensive aquaculture due to their ability to breathe air, their rapid growth and efficient food conversion (Hogendoorn 1981; Colman et al. 1982; Diana et al. 1988). Research with Clarias has often resulted in yields much lower than those achieved by commercial culture systems (Colman et al. 1982; Tarnchalanukit et al. 1983; Yamada 1985; Diana and Fast 1989). Lower yields under laboratory conditions have been attributed to generally higher level of handling stress applied to fishes in research (Diana and Fast 1989).

The purpose of this study was to determine the effects of feeding frequency on assimilation efficiency and consumption, and the effect of handling stress on yield of Clarias fuscus in intensive tank culture. The first hypothesis, tested during experiment 1 , was that multiple feedings per day result in improved growth and assimilation efficiency compared to a single meal of similar ration. The second hypothesis, tested during experiment 2 , was that multiple satiation feedings per day result in increased growth and daily food consumption. The third hypothesis, tested during both experiments, was that handling stress causes decreased growth and increased mortality, and thus an overall decrease in yield.

\section{Materials and Methods}

\section{Facilities}

The experiments were conducted in 18 fiberglass tanks at the Mariculture Research and Training Center, Hawaii Institute of
Marine Biology, Kaneohe, Hawaii. Tank dimensions were $1.04 \mathrm{~m}$ long $\times 0.61 \mathrm{~m}$ wide. Water depths and volumes were held constant at $0.38 \mathrm{~m}$ and $0.24 \mathrm{~m}^{3}$, respectively. System water was pumped from a 1.0 ha pond to a supply tank $\left(0.5 \mathrm{~m}^{3}\right)$ which fed each experimental tank by gravity flow. Pond water passed through a $0.7 \mathrm{~m}$ packed column before entering the supply tank, thus maintaining dissolved gases in the influent water at or near air saturation. Water flow rate to each tank was controlled to provide approximately 24 turnovers per day for all experiments. All experimental tanks were also completely drained then refilled daily throughout the study. Overflow water was returned to the supply pond. Total alkalinity of the pond water ranged from 136-138 $\mathrm{mg} / \mathrm{L}$ and salinity was $0.0 \mathrm{ppt}$. The pond contained macrophytes, Oreochromis mossambicus, Gambusia sp., and tadpoles. Water quality in the supply pond was conditioned by the biotic communities, inputs from a freshwater stream, and rainfall.

\section{Experiment 1: Assimilation Efficiency}

A $3 \times 2$ factorial experiment was conducted to determine the effect of feeding frequency on assimilation efficiency and the effect of handling on growth and mortality of Clarias fuscus. The design consisted of three feeding frequencies and two handling treatments. Fish were either handled weekly for measurements or left unhandled for the duration of the experiment. In feeding frequency treatments, the same daily ration was administered in one, two, or three meals. Three replicates per treatment were randomly assigned to 18 tanks.

On 2 June 1989, Clarias fuscus averaging $37.4 \mathrm{~g}$ (range 35.1-39.4) were randomly sorted and stocked at 210 fish per $\mathrm{m}^{3}$ (50 fish per tank). Fish were fed a complete diet of dry trout pellets (size \#4, sinking; Rangen, Inc., Buhl, Idaho; $45 \%$ crude protein, $16 \%$ fat) at a daily ration of $3.0 \%$ body weight per day $(\% \mathrm{bw} / \mathrm{d})$ for the duration of the experiment. This ration was chosen to ensure ingestion of all applied feed and to 
maintain a significant growth rate (Hogendoorn et al. 1983). A feeding tray was used once per week to determine if all applied food was eaten. The daily ration was administered in one (at $0800 \mathrm{~h}$ ), two (at 0800 and $1800 \mathrm{~h}$ ), or three (at 800,1300 , and $1800 \mathrm{~h}$ ) portions. Total quantity of feed was adjusted weekly for each treatment based on changes in biomass from all measured (handled) tanks combined. Experiment 1 continued for $34 \mathrm{~d}$.

Temperature and dissolved oxygen (DO) levels were measured every morning (0800 h) with a YSI meter (air-calibrated daily). Ammonium and nitrite concentrations were measured once per week (0800 h) using an autoanalyzer. When mortalities were discovered, they were discarded and not replaced. All undiscovered mortalities that occurred between weekly sampling were assumed to be eaten by surviving fish.

Fish handled weekly were flushed out the drain into a net, weighed in the net without blotting dry, and counted. This was the minimum level of handling required to permit weekly adjustment of ration and is similar to the level of handling used by Diana and Fast (1989). Weekly fish measurements included total biomass, total number, and mean weight per individual (biomass/number) in each tank designated for handling. Daily mortality rates were calculated in percent per day $(\% / d)$ as:

$$
100 \cdot\left(\mathbf{N}_{\mathrm{t}}-\mathbf{N}_{\mathrm{t}-1}\right) /\left(\mathbf{N}_{\mathrm{t}-1} \cdot \mathrm{d}\right)
$$

where $N_{t}=$ current number surviving in that tank, $N_{t-1}=$ number in that tank at time $t-1$, and $d=$ number of days. Daily mean specific growth was calculated in percent of body weight per day ( $\% \mathrm{bw} / \mathrm{d})$ as:

$$
100 \cdot\left(W_{t}-W_{t-1}\right) /\left(W_{t-1} \cdot d\right)
$$

where $W_{t}=$ current mean weight and $W_{t-1}$ $=$ mean weight at time $\mathrm{t}-1$. Feed conversion efficiency was calculated as:

$$
\begin{aligned}
\text { FCE }= & \text { food applied } \\
& (\text { dry g)/fish growth } \\
& (\text { wet g) }
\end{aligned}
$$

Depensatory growth is common in fishes and results from dominant individuals consuming more food and growing faster than their subordinates. If depensatory growth occurs, the variation in size of fish will increase as an experiment progresses. Coefficients of variation in fish growth were calculated overall for each feeding frequency or handling treatment as:

$$
\left(100 \cdot \mathrm{SD}_{\mathrm{WT}}\right) / \mathrm{W}
$$

where $\mathrm{SD}_{\mathrm{wT}}=$ standard deviation of the weight of all fish in a treatment at harvest, and $\mathrm{W}=$ overall mean weight for that group at harvest (Yamagishi 1969).

Overall treatment effects were tested for significance by Analysis of Variance, which required necessary assumptions of normality and homogeneity. Residuals were plotted against predicted values to examine homogeneity. Lilliefors test, skewness and kurtosis coefficients, and the normal plot were used to examine normality. All multiple comparisons were done using Scheffe's S-method (Neter et al. 1985). Data were analyzed using SYSTAT (Wilkinson 1987). Statements of significance refer to $P<0.05$.

\section{Experiment 2: Maximum Daily Ration}

A $2 \times 2$ factorial design was used to determine the effect of feeding frequency on maximum daily ration $\left(Q_{R_{\max }}\right)$. The design included 2 feeding frequencies and 2 handling treatments. Unhandled treatments included 2 replicates, while handled treatments were not replicated, but were necessary to enable ration size readjustment for fish growth. Fish were fed to satiation at one $(0800 \mathrm{~h})$ or two feedings (0800 and $1800 \mathrm{~h}$ ) per day. Use of floating feed allowed maximum feeding without reducing water quality, and excess feed was removed after $45 \mathrm{~min}$. The following equation was used to estimate feeding rate (based on data from Tarnchalanukit et al. 1983):

$$
\mathrm{Q}_{\mathrm{Rmax}}=0.23 \mathrm{~W}^{0.78}
$$

(Diana et al. 1988), where $\mathrm{W}=$ wet body weight $(\mathrm{g})$, and $\mathrm{Q}_{\mathrm{Rmax}}$ is in $\mathrm{kcal} / \mathrm{d}$. 
TABLE 1. Mean initial fish weight ( $g / f$ ish), final weight ( $g / f i s h)$, mortality rate $(\% / d)$, and specific growth rate (\% $b w / d)$ of Clarias fuscus fed 1, 2 or 3 feedings per day; and either handled weekly or left unhandled in experiment 1. Total daily ration $\left(Q_{R}\right)$ equaled $3.0 \% \mathrm{bw} / \mathrm{d}$ for all lanks. Mean (standard error).

\begin{tabular}{ccccc}
\hline $\begin{array}{c}\text { Feeding } \\
\text { fre- } \\
\text { quency }\end{array}$ & $\begin{array}{c}\text { Initial } \\
\text { weight }^{c}\end{array}$ & $\begin{array}{c}\text { Final } \\
\text { weight }\end{array}$ & $\begin{array}{c}\text { Mortality } \\
\text { rate }^{,, d}\end{array}$ & $\begin{array}{c}\text { Specific } \\
\text { growth }^{\mathbf{a}, \mathbf{b}, \mathbf{d}}\end{array}$ \\
\hline & & Handled & & \\
1 & $36.32(0.58)$ & $68.15(2.12)$ & $0.059(0.034)$ & $2.58(0.20)$ \\
2 & $37.56(0.70)$ & $75.29(2.12)$ & $0.118(0.059)$ & $2.95(0.09)$ \\
3 & $37.02(1.26)$ & $79.73(2.60)$ & $0.118(0.068)$ & $3.40(0.13)$ \\
& & Unhandled & & \\
1 & $37.50(0.34)$ & $78.39(2.71)$ & $0.118(0.059)$ & $3.21(0.20)$ \\
2 & $37.50(0.50)$ & $82.76(1.15)$ & $0.157(0.039)$ & $3.55(0.01)$ \\
3 & $38.56(0.34)$ & $84.14(0.33)$ & $0.118(0.059)$ & $3.48(0.08)$ \\
\hline
\end{tabular}

a Significant difference between handling treatments.

b Significant difference between feeding treatments.

c No significant difference among treatments.

d No significant interactions between feeding frequency and handling.

Clarias fuscus individuals from experiment 1 were randomly mixed and conditioned for two weeks to accept floating dry trout pellets $(40 \%$ crude protein, $10 \%$ fat; Purina Mills, Inc., St. Louis, Missouri) which provided a complete diet. On 23 July 1990, fish were randomly restocked into experimental tanks at 210 fish per $\mathrm{m}^{3}$ (50 fish per tank). Individual weight at stocking averaged $78.2 \mathrm{~g}$ (range 75.5-82.9). Temperature and DO were recorded for one experimental tank and for the water supply tank. Other water chemistry parameters were measured as in experiment 1 . Measurements of fish and ration adjustments were conducted weekly. Experiment 2 was conducted for 29 d. Initial and final fish measurements, mortality rates, specific growth rates and coefficients of variation were determined as in experiment 1 . FCE could not be calculated in experiment 2 because exact amounts consumed were not determined. Since food was applied in excess, some waste probably occurred. Coefficients of variation for handling effects could not be calculated, since handled treatments were not replicated.

An important assumption for experiment 2 , which was tested in experiment 1 , was that assimilation efficiency remained equal among treatments of 1 or 2 feedings per day.
To determine whether differences in assimilation efficiency could have occurred in treatments of experiment 2, two feeding frequency treatments at a total daily ration of $1.5 \% \mathrm{bw} / \mathrm{d}$ were again used as a control. Fish were given one feeding of $1.5 \% \mathrm{bw} / \mathrm{d}(0800$ h) or two feedings of $0.75 \% \mathrm{bw} / \mathrm{d}$ ( 0800 and $1800 \mathrm{~h}$ ) per day.

Overall treatment effects in experiment 2 were tested, and data analyzed, as in experiment 1 . Statistics could not be done on the effects of handling, since handled treatments were not replicated.

\section{Results}

\section{Experiment 1: Assimilation Efficiency}

Specific growth rates of Clarias fuscus decreased only slightly with time, indicating that carrying capacity was never reached in the tanks during experiment 1 . At a fixed total daily ration, three feedings resulted in significantly faster growth (19\% greater) than fish fed single feedings (ANOVA2, $P<0.05$; Table 1). Differences in growth between fish fed once or twice per day, as well as differences between fish fed two and three times per day, were not significant. All food administered appeared to be completely ingested, except in tanks containing fish which had recently been handled. 
Handling of Clarias fuscus significantly reduced growth in experiment 1 for fish fed once or twice a day; but it had no apparent effect on growth of fish fed 3 times per day (ANOVA2, $P<0.05$ ). However, no significant interactions were detected between feeding frequency and handling related to either growth or mortality (ANOVA2, $P>$ $0.05)$. Neither handling nor feeding frequency significantly affected mortality (ANOVA2, $P>0.05$; Table 1). Mean water temperature $(28 \mathrm{C})$ and mean DO $(6.7 \mathrm{mg} /$ L) remained relatively constant throughout experiment 1 , and were not significantly different among treatments (ANOVA1, $P>$ 0.05 ). Other water quality parameters which were measured were within acceptable ranges for fish culture. Mean FCEs were 1.46, 1.31 , and 1.20 for fish fed 1,2 , and 3 feedings per day, respectively. Mean FCEs were 1.22 and 1.42 for fish in unhandled and handled treatments, respectively (all feeding frequencies combined).

Coefficients of variation calculated for Clarias fuscus growth in experiment 1 were $9.33 \%, 2.68 \%$, and $5.20 \%$ for fish fed 1,2 , and 3 feedings per day, respectively. Coefficients of variation were $6.4 \%$ for handled and $5.0 \%$ for unhandled treatments, respectively.

\section{Experiment 2: Maximum Daily Ration}

Clarias fuscus given 2 satiation feedings per day grew $47 \%$ faster than those given 1 satiation feeding per day (ANOVA2, $P<$ 0.05 ; Table 2). No mortalities occurred during experiment 2 , and growth rate was not apparently affected by handling. No significant interactions were detected between feeding frequency and handling related to growth (ANOVA2, $P>0.05$ ).

Although consumption was not measured directly, actual $\mathrm{Q}_{\mathrm{Rmax}}$ levels appeared to be much lower (estimated at $30 \%$ lower) than those calculated using equation 4 , at least for fish fed once per day. Actual meal size for fish fed twice per day was always smaller at the second daily feeding than the first.

As in experiment 1 , there were no signif-
TABLE 2. Mean initial weight ( $g / f$ ish), final weight ( $g$ / fish), and specific growth rate (\% bw/d) of Clarias fuscus fed 1 or 2 feedings per day, and either handled weekly or left unhandled during experiment 2.

\begin{tabular}{lccc}
\hline Handling & $\begin{array}{c}\text { Initial } \\
\text { weight }^{\mathrm{a}, \mathrm{c}}\end{array}$ & $\begin{array}{c}\text { Final } \\
\text { weight }^{\mathrm{a}, \mathrm{c}}\end{array}$ & $\begin{array}{c}\text { Specific } \\
\text { growth }^{\mathrm{a}, \mathrm{b}}\end{array}$ \\
\hline Yes & $\mathbf{3}$ & 1 Feeding \\
Yes & 76.6 & 108.4 & 1.06 \\
No & 76.1 & 97.6 & 0.95 \\
& & 103.3 & 1.24 \\
Yes & 78.9 & 118.6 & 1.74 \\
Yes & 75.5 & 106.7 & 1.43 \\
No & 79.5 & 115.2 & 1.55 \\
\hline
\end{tabular}

a Significant difference between feeding treatments.

b No significant difference between feeding treatments.

c No significant difference between handling treatments.

icant differences in growth of fish fed a fixed daily ration in 1 or 2 feedings per day (ANOVA2, $P>0.05$ ). Again, final weight achieved was not significantly reduced by handling under these treatments (ANOVA2, $P>0.05$ ), and no significant interactions were detected between feeding frequency and handling (ANOVA2, $P>0.05$ ). Coefficients of variation for Clarias growth rates in experiment 2 were $18.0 \%$ and $6.7 \%$ for fish fed 1 or 2 feedings per day, respectively. FCE could not be accurately estimated in experiment 2 because food was applied in excess. Mean water temperature $(27.3 \mathrm{C}$ ) in experiment 2 did not differ significantly over time between the supply tank and an experimental tank (ANOVAl, $P>0.05$ ). DO showed significant differences between the supply tank $(6.7 \mathrm{mg} / \mathrm{L})$ and experimental tank $(5.4 \mathrm{mg} / \mathrm{L})$ over time (ANOVA $1, P<$ 0.05 ). Other water chemistry parameters were within acceptable ranges.

\section{Discussion}

Three feedings per day, at a fixed daily ration, significantly increased growth rate of Clarias fuscus compared to a single feeding in experiment 1. All food administered to fish in experiment 1 appeared to be ingested. 
These results are hypothesized to demonstrate an increase in assimilation efficiency with multiple feedings per day. This increased assimilation efficiency is comparable to studies on other fish (Huisman 1974; Andrews and Page 1975; Hogendoorn 1981; Marian et al. 1981).

Daily ration calculations were based on initial stocking densities of fish in experiment 1 , because mortality rate in each tank was unknown. After some mortality had occurred, the rations administered per fish were slightly higher than intended. Since there were no significant differences in mortality among treatments, and mortality was relatively minor, individual daily ration was still approximately equal among treatments.

The hypothesis that 2 satiation feedings per day would result in higher growth rate of Clarias fuscus than 1 satiation feeding per day was supported by data from experiment 2 , since there were large differences in growth among treatments. Data from both experiments indicated no significant differences in growth between fish fed a fixed daily ration administered in either 1 or 2 feedings per day (but not for fish fed 3 meals per day). Thus, assimilation efficiency was probably equal among treatments in experiment 2. The differential growth between treatments indicates an increase in daily voluntary food consumption by Clarias fuscus with multiple feedings per day. If metabolic demands were similar among treatments, then the amount of increased consumption for fish fed twice per day would be directly proportional to their increased growth rate. Changing metabolic demands could alter this extrapolation somewhat. Higher daily consumption for fish fed two meals a day would more likely increase metabolism rather than decrease it, due to higher deamination costs and apparent specific dynamic action; thus, fish in multiple meal treatments might have higher metabolic demands. Since these fish also grew much better, their daily food consumption could have been even higher than would be estimated for fish with similar metabolic demands. Increased consumption with higher meal frequencies has also been demonstrated for other fishes (Andrews and Page 1975; Grayton and Beamish 1977; Lovell 1979; Hogendoorn 1981; Marian et al. 1981; Sampath 1984).

Fish offered 2 satiation feedings per day in experiment 2 appeared to consistently consume a much smaller amount during the second meal. Windell (1978) showed that increased feeding frequency tended to result in either a reduction of individual meal size or defecation of material before being fully digested (i.e., lower assimilation efficiency). However, large increases in growth rate resulting from multiple feedings in experiment 2 indicate that any possible assimilation differences, if they occurred at satiation feeding, were more than compensated for by increased consumption.

Equation 4 consistently overestimated $\mathrm{Q}_{\mathrm{Rmax}}$ for Clarias in experiment 2. This equation was based on data from Thailand, where normal culture temperatures exceed 30 C (Diana and Fast 1989). Mean overall water temperature during experiment 2 was $27.3 \mathrm{C}$, which is lower than the temperatures at which data for equation 4 were collected; thus $\mathrm{Q}_{\mathrm{Rmax}}$ would be expected to be somewhat lower in the present study (Brett 1979). In addition, equation 4 is based on sinking pelleted feed which probably was of different proximate composition than that used in experiment 2 . Overestimation of $Q_{R \max }$ was acceptable, however, as a method of satiation feeding for experiment 2 .

In both experiments, behavioral interactions or individual differences in appetite appear to have affected growth in relation to feeding frequency. Coefficients of variation from both experiments indicated that fish given 1 feeding per day exhibited a higher level of depensatory growth, particularly in experiment 2 . In addition to the benefits of better food conversion and faster growth, multiple feedings per day may also result in more uniform growth rates among individual Clarias. 
Handling stress caused decreased growth and less efficient feed conversion for Clarias fuscus in experiment 1 , in which fish grew from an initial mean weight of $37 \mathrm{~g}$ to 78 g. Experiment 2 indicated no significant differences in growth or mortality related to handling stress. The effect of handling stress on cultured Clarias fuscus may change with size (or age). Diana and Fast (1989) found that cultured Clarias weighing less than 20 g exhibited much higher mortality rates than those over $20 \mathrm{~g}$, which they attributed in part to poor water quality. When water quality was good in the present study, handling stress reduced growth, but did not affect mortality for Clarias fuscus larger than $20 \mathrm{~g}$. In fish over $80 \mathrm{~g}$, handling stress had no effect on growth either. The exact effect of handling stress on growth of Clarias less than $80 \mathrm{~g}$ in size is uncertain, although meals were not fully consumed immediately after handling. Food consumption may decrease in stressful situations (Peter 1979). In addition, increased levels of excitement which accompany handling may increase metabolic costs.

Feeding multiple meals for Clarias fuscus resulted in better assimilation efficiency and increased daily food consumption. The former improved feed conversion somewhat (19\%), while the latter increased maximum growth rate dramatically (45\%). Both may be used in commercial culture to improve feeding economy. However, these variables likely change with fish size and temperature, so that more detailed experiments are required to optimize feeding systems for Clarias.

\section{Acknowledgments}

This study was done by the first author in partial fulfillment of requirements for a Master of Science degree at the University of Michigan. This work was partially funded by the Pond Dynamics/Aquaculture CRSP supported by the Agency for International Development Grant No. DAN-4023-G-SS2074-00. B. Alexander, R. Cantrell, J. Ebeling, K. Hashimoto, C. LaFranchi, M. Lyum,
M. Sayoc, A. Santos, and B. Santos all assisted in field and laboratory work. B. Diana assisted in manuscript preparation.

\section{Literature Cited}

Andrews, J. W. and J. W. Page. 1975. The effects of frequency of feeding on culture of channel catfish. Transactions of the American Fisheries Society 104:317-321.

Brett, J. R. 1971. Satiation time, appetite, and maximum food intake of sockeye salmon (Oncorhynchus nerka). Journal of the Fisheries Research Board of Canada 28:409-415.

Brett, J. R. 1979. Environmental factors and growth. Pages 599-675 in W. S. Hoar, D. J. Randall, and J. R. Brett, editors. Fish physiology, volume VIII. Academic Press, New York, New York, USA.

Colman, J. A., V. Srisuwantach, S. Boonyaratpalin and S. Chinabut. 1982. Pond management, water environment and fish grow-out performance relationships in Clarias culture trials. National Inland Fisheries Institute, Kasetsart University, Bangkok, Thailand.

Diana, J. S. and A. W. Fast. 1989. The effects of water exchange rate and density on yield of walking catfish, Clarias fuscus. Aquaculture 78:267276.

Diana, J. S., S. L. Kohler and D. R. Ottey. 1988. A yield model for walking catfish production in aquaculture systems. Aquaculture 71:23-35.

Grayton, B. D. and F. W. H. Beamish. 1977. Effects of feeding frequency on food intake, growth, and body composition of rainbow trout (Salmo gairdneri). Aquaculture 11:159-172.

Hogendoorn, H. 1981. Controlled propagation of the African catfish, Clarias lazera (C. \& V.). IV. Effect of feeding regime in fingerling culture. Aquaculture 24:123-131.

Hogendoorn, H., J. A. J. Jansen, W. J. Koops, M. A. M. Machiels, P. H. Van Ewijk, and J. P. Van Hees. 1983. Growth and production of the African catfish, Clarias lazera (C. \& V.). II. Effects of body weight, temperature, and feeding level in intensive tank culture. Aquaculture 34:265-285.

Huisman, E. A. 1974. Optimalisering van de groei bij de karper, Cyprinus carpio L. Dessertatie, Wageningen.

Lovell, T. 1979. Factors affecting voluntary food consumption by channel catfish. Pages 555-564 in J. E. Halver and $\mathbf{K}$. Tiews, editors. Finfish nutrition and fishfeed technology, volume I. Heeneman Verlagsgesellschaft, Berlin, Germany.

Marian, M. P., A. G. Ponniah, R. Pitchchairaj and M. Narayanan. 1981. Effect of feeding frequency on surfacing activity and growth in the air-breathing fish, Heteropneustes fossilis. Aquaculture 26:237244. 
Neter, J., W. Wasserman and M. H. Kutner. 1985. Applied linear statistical models, 2nd edition. Richard D. Irwin, Inc., Homewood, Illinois, USA.

Peter, R. E. 1979. The brain and feeding behavior. Pages 121-159 in W. S. Hoar, D. J. Randall, and J. R. Brett, editors. Fish physiology, volume VIII. Academic Press, New York, New York, USA.

Sampath, K. 1984. Preliminary report on the effects of feeding frequency in Channa striatus. Aquaculture 40:301-306.

Tarnchalanukit, W., W. Chuapoehuk, P. Suraniranat and U. NaNakorn. 1983. Pla duk dan culture in circular concrete ponds with water recirculating system. Department of Agriculture, Faculty of Fisheries, Kasetsart University, Bangkok, Thailand.

Webb, P. W. 1978. Partitioning of energy into metabolism and growth. Pages 184-214 in S. D. Gerking, editor. Ecology of freshwater fish pro- duction. John Wiley and Sons, New York, New York, USA.

Wilkinson, L. 1987. SYSTAT: The system for statistics. SYSTAT, Inc., Evanston, Illinois, USA.

Windell, J. T. 1978. Digestion and the daily ration of fishes. Pages 159-183 in S. D. Gerking, editor. Ecology of freshwater fish production. John Wiley and Sons, New York, New York, USA.

Yamada, R. 1985. Pond production systems: stocking practices in pond fish culture. Pages 85-96 in J. E. Lannan, R. O. Smitherman and G. Tchobanoglous, editors. Principles and practices of pond aquaculture. Oregon State University Press, Corvallis, Oregon, USA.

Yamagishi, H. 1969. Postembryonal growth and its variability of the three marine fishes with special reference to the mechanism of growth variation in fishes. Research in Population Ecology 11:14-33. 